\title{
Influência das dimensões dos descolamentos de revestimentos cerâmicos na avaliação com termografia de infravermelho
}

\author{
Influence of detachment dimensions on the evaluation of \\ ceramic tiles with infrared thermography
}

\section{Diandra Tanaka \\ Elier Pavon}

\section{Resumo}

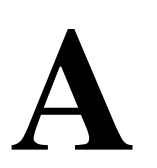

termografia de infravermelho constitui atualmente uma importante ferramenta nas inspeções de edifícios, principalmente na identificação e no diagnóstico de patologias em revestimentos argamassados e cerâmicos. No caso da avaliação de revestimentos cerâmicos com termografia de infravermelho, verifica-se que existem ainda muitas dúvidas em relação ao comportamento do Delta $\mathrm{T}$, principal parâmetro utilizado na análise das patologias nos termogramas, devido à influência do tipo e das dimensões das manifestações patológicas estudadas com essa técnica. Nesse contexto, o presente estudo analisou a influência das dimensões de descolamentos em revestimentos cerâmicos na avaliação termográfica. Para tal fim, foi construído um protótipo de alvenaria com revestimento cerâmico onde foi simulada a presença de descolamentos, sendo o protótipo avaliado em ambiente externo em diferentes orientações solares, num período de 4 dias em 3 anos consecutivos. Os resultados mostraram que os máximos valores de Delta $T$ na inspeção termográfica foram obtidos nos momentos de máximo crescimento da temperatura da superfície revestida nas quatro orientações solares. Após a análise estatística, concluiu-se que diferenças na largura e, consequentemente, na área dos defeitos terão maior probabilidade de ser detectadas, o que facilita a avaliação do desempenho de sistemas de revestimento cerâmico externos com a termografia de infravermelho.

Palavras-chave: Termografia infravermelha. Patologia. Descolamento. Revestimento. Placa cerâmica.

${ }^{1}$ Diandra Tanaka ${ }^{1}$ Universidade Federal do Oeste da Bahia Barreiras - BA - Brasil

${ }^{2}$ Elier Pavon 2Universidade Federal do Oeste da Bahia Barreiras - BA - Brasil

\section{Abstract}

Infrared thermography is currently an important tool in building inspections, mainly in the identification and diagnosis of pathologies in mortar and ceramic coverings. In the case of the evaluation of ceramic tiles with infrared thermography, it appears many questions still remain regarding the behavior of Delta T, the main parameter used in the analysis of pathologies in thermograms, due to the influence of the type and dimensions of the pathological manifestations studied with this technique. This study evaluated the influence of the dimensions of the detachments of ceramic tiles in the thermographic evaluation. For this purpose, a masonry prototype with ceramic tile covering was built, where the presence of detachments was simulated, and then evaluated in an external environment in different solar orientations, during a four-day period in in three consecutive years. The results showed that the maximum values of Delta $T$ in the thermographic inspection were obtained at the moments of maximum increase of the covering surface temperature in the four solar orientations. After the statistical analysis, it was concluded that differences in width and, consequently, in the defects' area, are more probable to be detected, which facilitates the evaluation of the performance of facade systems using infrared thermography.

Keywords: Infrared thermography. Pathology. Detachment. Covering. Ceramic tile. 


\section{Introdução}

Técnicas de inspeção não destrutivas são importantes para diagnósticos precoces de materiais, elementos e componentes a fim de eliminar defeitos e reduzir custos de reparo (BARREIRA; FREITAS, 2007). A termografia de infravermelho é uma técnica de ensaio não destrutiva que pode ser utilizada no diagnóstico de patologias como umidade (EDIS; FLORES-COLEN; BRITO, 2014, 2015b; KOMINSKY et al., 2007; ROCHA et al., 2018; SANTOS et al., 2019), fissuração (BAUER et al., 2016b; BAUER; MILHOMEM; AIDAR, 2018; DUFOUR; DEROME; ZMEUREANU, 2009; SHAM; CHEN; LONG, 2008) e descolamento (BAUER et al., 2016a; COTIČ et al., 2015; EDIS; FLORES-COLEN; BRITO, 2012, 2015a; LOURENÇO; MATIAS; FARIA, 2017), na avaliação de desempenho térmico de edificações (COELHO et al., 2017; FERRARINI et al., 2016; YOUCEF et al., 2012), no auxílio em procedimentos de manutenções, no exame de sistemas de aquecimento, telhados, anomalias elétricas e mecânicas, na detecção de objetos enterrados, na vigilância e na inspeção de edifícios (BAGAVATHIAPPAN et al., 2013; GARRIDO et al., 2020), entre outras aplicações.

Contudo, essa técnica tem potenciais ainda não explorados completamente, como a detecção e avaliação de descolamentos em fachadas de edificações, para a qual ainda não existe um procedimento normatizado (PAVÓN, 2017), justificado pela influência das variáveis envolvidas na avaliação térmica dessa patologia. Entre as principais variáveis envolvidas na aplicação dessa técnica podem ser citados o melhor horário para realizar a inspeção, o quanto a orientação solar da fachada pode interferir no resultado das medições e como as características dos defeitos influenciam a interpretação dos termogramas.

Por tais motivos, pesquisas recentes se dedicam a encontrar padrões de comportamento e critérios que possam melhorar a forma de avaliação dessa patologia e, consequentemente, a interpretação dos resultados. Nessa linha do conhecimento, encontram-se estudos que fazem inspeções termográficas ao longo do dia (FOX et al., 2015; LOURENÇO; MATIAS; FARIA, 2017) ou de dias (IBARRA-CASTANEDO et al., 2017), que se apoiam em simulações do clima e nas características do elemento (EDIS; FLORES-COLEN; BRITO, 2014, 2015a) e que utilizam ferramentas matemáticas consolidadas em outras áreas na interpretação dos termogramas (IBARRA-CASTANEDO et al., 2017) com o fim de definir o momento de fazer a inspeção e de analisar a influência do tipo e das dimensões dos defeitos.

O presente estudo teve por objetivo analisar a influência das dimensões dos descolamentos na avaliação de revestimentos cerâmicos com termografia de infravermelho nas quatro orientações solares, construindo-se para tal fim um protótipo de alvenaria revestido com placas cerâmicas onde se simulou a presença de descolamentos.

\section{Referencial teórico}

Os descolamentos podem ser estudados com a termografia de infravermelho devido à espessura relativamente pequena da maioria dos materiais de revestimento e à presença de ar entre as camadas aplicadas como resultado da perda de aderência com o substrato, fatos que justificam o estudo desse fenômeno. A presença de ar perto da superfície gera nessa área diferenças de temperatura quando comparado com uma área vizinha em condições normais, o que permite a identificação dessa patologia. Pelas variáveis envolvidas relativas às dimensões do defeito, ao material e às condições de exposição, a identificação dessa patologia com a termografia se torna bem complexa.

Chew (1998) utilizou a termografia infravermelha para avaliar fachadas de edifícios e realçou a importância das condições ambientais para aplicar a técnica. No estudo de laboratório realizado por Cheng, Cheng e Chiang (2008) foram avaliadas placas de concreto com vazios cúbicos em seu interior, para analisar a influência da profundidade do defeito (dimensão lateral) a partir do comportamento dos valores do Delta T. Para um mesmo tamanho de defeito $(10 \mathrm{~cm})$ e igual intensidade do fluxo de calor, os defeitos mais próximos da superfície apresentaram maiores valores de Delta T. No estudo foi possível identificar vazios a uma profundidade de $3 \mathrm{~cm}$. Os valores do Delta $\mathrm{T}$ obtidos estiveram na faixa de $1{ }^{\circ} \mathrm{C}$ a $4,5{ }^{\circ} \mathrm{C}$ para um aquecimento intenso de aproximadamente $5 \mathrm{~min}$.

No laboratório, a possibilidade de empregar a termografia na avaliação de descolamentos em revestimentos com placas de granito foi analisada por Cerdeira et al. (2011). Os descolamentos apareceram como áreas mais frias na imagem devido ao fato de o aquecimento ter sido pela parte traseira da parede. Em placas de 20 $\mathrm{mm}$ de espessura e com uma diferença de $10^{\circ} \mathrm{C}$ entre o ar interno e o externo, conseguiram localizar defeitos de até $90 \mathrm{~mm}$ de diâmetro. Os autores indicaram que é possível estabelecer normas para a aceitação e rejeição desses revestimentos e condições para a criação de bases de dados com a evolução temporal da 
análise térmica do edifício. Mario (2011) detectou diversas áreas com descolamento de revestimento em argamassa de uma edificação. As inspeções foram feitas com baixa incidência do sol na fachada, e os descolamentos apareceram como áreas mais quentes nos termogramas. Já Simões et al. (2012) utilizaram a termografia infravermelha para examinar descolamentos de diferentes dimensões induzidos na camada adesiva de revestimento cerâmico sob ambiente controlado, em laboratório, tendo obtido valores positivos para defeitos maiores que $1,5 \mathrm{~cm}$.

Silva (2012) e Freitas, Freitas e Barreira (2014) conseguiram detectar descolamentos em revestimentos de gesso polimérico no laboratório e no campo. Freitas, Freitas e Barreira (2014) concluíram que os descolamentos no revestimento de gesso eram mais visíveis nos termogramas sob temperaturas mais elevadas. No estudo, o Delta $\mathrm{T}$ foi positivo durante a etapa de aquecimento, e negativo durante a etapa de arrefecimento, com valores no intervalo de $0,4^{\circ} \mathrm{C}$ a $2,5^{\circ} \mathrm{C}$ durante o período de aquecimento.

No estudo realizado por Caldeira et al. (2015) foram identificadas falhas de aderência simuladas em superfícies de concreto aquecidas por lâmpadas incandescentes. Os discos de EPS (poliestireno expandido) inseridos para simular os danos foram detectados como áreas mais quentes durante o período de aquecimento, chegando o valor de Delta $\mathrm{T}$ a $3,7^{\circ} \mathrm{C}$.

Fox et al. (2015) avaliaram um descolamento no revestimento em argamassa de uma parede construída de adobe. Foi determinado o Delta $\mathrm{T}$ a partir da representação das linhas de temperatura durante o final da tarde, da noite e da madrugada. Como nesses horários o fluxo de calor está saindo da superfície da fachada para o exterior, a presença de um descolamento no revestimento foi detectada com valores negativos. Concluíram que não é indicado nenhum intervalo temporal único para avaliação termográfica de descolamentos em todas as circunstâncias.

Em placas cerâmicas do tipo porcelanato de cores branca e preta, Lourenço, Matias e Faria (2017) detectaram descolamentos utilizando a termografia de infravermelho. Durante o dia, os descolamentos apareceram como áreas mais quentes nos termogramas, e, à noite, como áreas mais frias, com valores na faixa de $0,8{ }^{\circ} \mathrm{C}$ a $3,1^{\circ} \mathrm{C}$. Concluíram que se devem procurar os descolamentos durante o início da incidência solar na fachada ou no início do período de arrefecimento, ou seja, após o início do sombreamento da parede.

Este artigo examina, através da termografia de infravermelho, descolamentos cerâmicos induzidos em uma parede experimental utilizando como fonte de calor a radiação solar para as quatro orientações solares. Apresentam-se gráficos comparativos das quatro situações e seus resultados com o intuito de analisar estatisticamente a influência das dimensões dos descolamentos na avaliação termográfica dessa patologia.

\section{Método}

\section{Confecção dos protótipos}

Construiu-se um protótipo de parede com $60 \mathrm{~cm}$ de altura por $60 \mathrm{~cm}$ de largura composto de blocos cerâmicos furados de $9 \mathrm{~cm}$ de espessura. Utilizou-se argamassa de assentamento de $1 \mathrm{~cm}$ de espessura nas juntas horizontais e verticais, e revestimento em camada única de $2 \mathrm{~cm}$ de espessura nas duas faces. Uma das faces foi revestida com seis placas cerâmicas brancas, e o restante do substrato aparente foi revestido com pintura acrílica na cor branca, para uniformizar a coloração da parede. As placas cerâmicas de 16,5x15,5x0,5 $\mathrm{cm}$ utilizadas no protótipo foram obtidas mediante o corte de placas do tipo grês (Blb), com dimensões de 46x33x0,5 cm. Para o assentamento das placas cerâmicas, foi utilizada argamassa colante do tipo ACIII.

A padronização através da coloração branca é necessária para simular a pior condição possível durante a avaliação termográfica. Os baixos valores de absortância térmica dos revestimentos brancos diminuem a absorção de calor na superfície do revestimento e, consequentemente, o fluxo de calor que atravessa a parede. Quanto menor o fluxo de calor, menores as diferenças de temperatura entre as áreas com e sem defeito, o que dificulta a visibilidade do defeito. A sequência construtiva seguida é apresentada na Figura 1.

A estrutura de madeira serviu como suporte rígido para permitir o transporte da parede, enquanto as placas de isopor instaladas em todo o seu contorno induziram a passagem do calor, majoritariamente perpendicular à parede.

Representa-se a parede construída na Figura 2, inclusive os defeitos embutidos nas placas 1, 3, 4 e 6, que, sob a área tracejada, não contêm argamassa colante, variando em largura $(2,5 \mathrm{~cm}$ e $5,0 \mathrm{~cm})$ e profundidade $(0,5 \mathrm{~cm}$ e $1,0 \mathrm{~cm})$. As placas 2 e 5 não apresentam defeito e foram usadas como referência para a aferição da temperatura média do revestimento. 
Figura 1 - Sequência construtiva da parede de alvenaria: (a) construção da estrutura de madeira; (b) instalação de isopor ao redor da alvenaria; (c) levantamento da alvenaria de bloco cerâmico; (d) revestimento com argamassa; (e) aplicação das placas cerâmicas; e (f) pintura da área no entorno da cerâmica

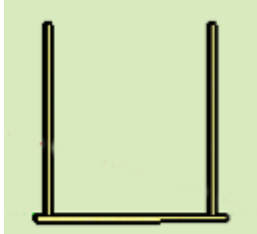

(a)

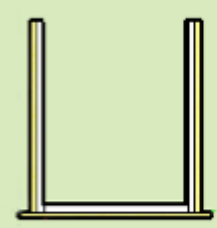

(b)

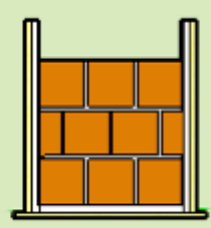

(c)

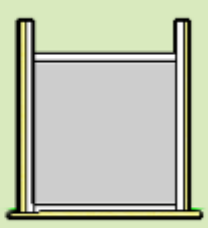

(d)

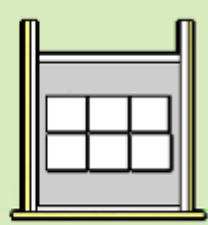

(e)

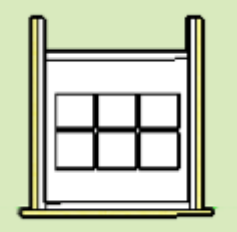

(f)

Figura 2 - Características dos defeitos inseridos no revestimento da parede

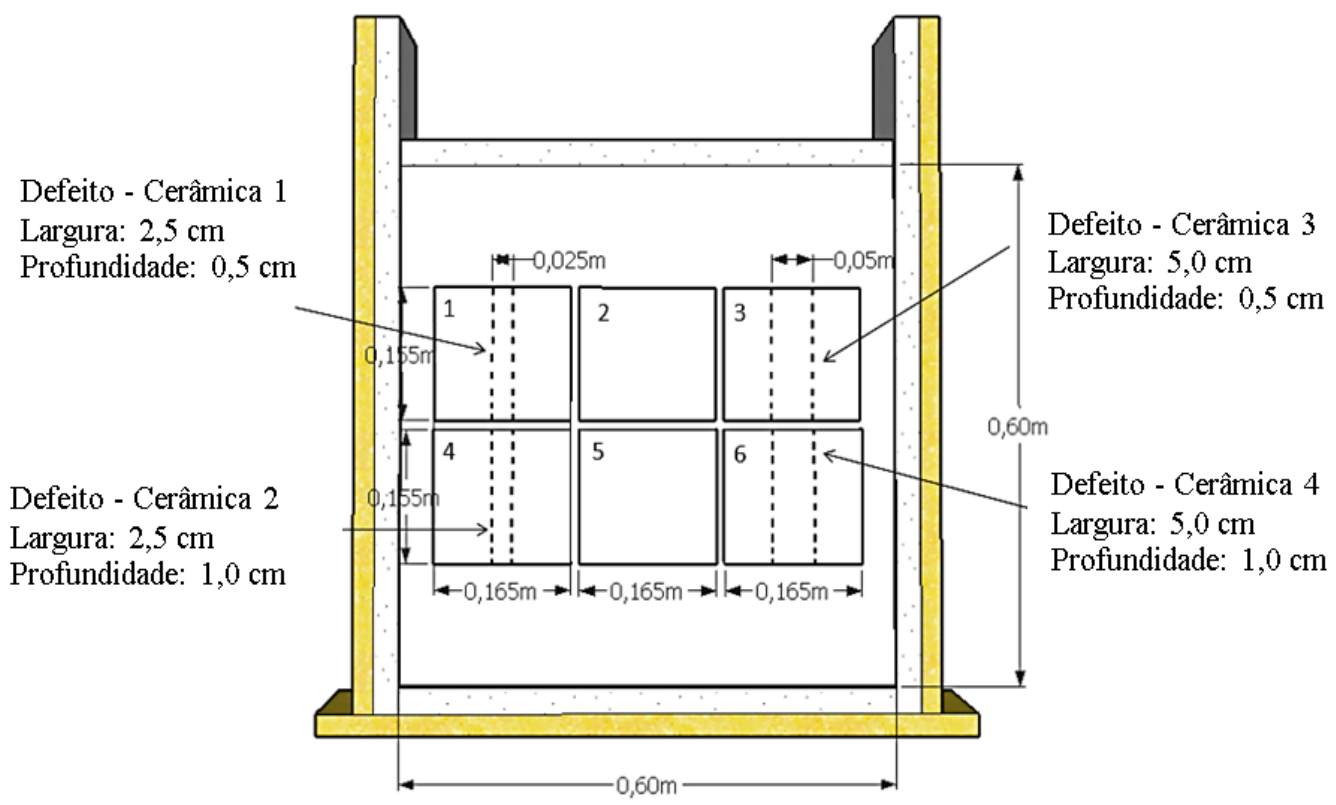

Na Figura 3 podem-se observar o defeito inserido no tardoz (falha de assentamento por ausência de argamassa colante) da placa cerâmica de número 3 instantes após o procedimento de colagem e a imagem digital do protótipo concluído.

A inspeção termográfica dos protótipos foi realizada ao ar livre, dedicando-se 4 dias por ano para o estudo do protótipo, sendo 1 dia para cada orientação solar. Após a inspeção termográfica realizada em 2016 (primeira sequência de ensaios), o processamento dos termogramas levou aproximadamente 6 semanas, o que tornou inviável a realização num único mês das três repetições. Desse modo, para manter bem próximas as condições climáticas, a inspeção foi realizada em 4 dias consecutivos no mês de agosto dos anos 2016, 2017 e 2018.

Os 4 dias de ensaio por ano foram escolhidos de modo que tivessem temperaturas na faixa de $18{ }^{\circ} \mathrm{C}$ a $35^{\circ} \mathrm{C}$, céu aberto durante todo o dia e ausência de chuvas. Em agosto de 2016 os 4 dias de ensaio tiveram temperaturas na faixa de $20{ }^{\circ} \mathrm{C}$ a $35^{\circ} \mathrm{C}$; em 2017 , na faixa de $19{ }^{\circ} \mathrm{C}$ a $34{ }^{\circ} \mathrm{C}$; e em 2018 , na faixa de $18{ }^{\circ} \mathrm{C}$ a $34{ }^{\circ} \mathrm{C}$. A escolha de amplitude térmica grande nos dias de ensaio, por volta dos $15^{\circ} \mathrm{C}$ aos $17{ }^{\circ} \mathrm{C}$, teve por objetivo que o ganho e/ou perda de calor da superfície revestida com e sem incidência do sol fosse o maior possível, para facilitar a análise da relação da variação de temperatura da superfície do revestimento com os valores de Delta T resultantes da inspeção termográfica.

O protótipo foi mantido dentro do laboratório durante os 3 anos, sendo exposto ao ambiente externo 5 dias por ano, os 4 dias de estudo mais o dia prévio à realização dos ensaios. A conservação no laboratório teve por objetivo evitar danos físicos ao protótipo e garantir que se encontrasse em condição seca nos dias de realização dos ensaios. Às $19 \mathrm{~h}$ do dia anterior ao primeiro dia do ensaio, o protótipo era deixado em área 
externa (local de ensaio) voltada para a orientação a ser estudada no dia seguinte, a fim de entrar em equilíbrio térmico com o meio. Nas medições subsequentes, no final do ensaio, às $19 \mathrm{~h}$, a parede era voltada para a orientação que seria ensaiada no dia seguinte.

No primeiro dia de ensaio, às $7 \mathrm{~h}$, foi capturada a primeira imagem com a câmera infravermelha, sendo as demais imagens realizadas a cada hora, até às $18 \mathrm{~h}$, totalizando doze imagens por dia (Figura 4 ). O mesmo procedimento foi realizado para as quatro orientações solares em 5 dias consecutivos nos meses de agosto de 2016, 2017 e 2018.

Para a inspeção (aquisição dos termogramas) foi utilizada a câmera infravermelha modelo Flir i3, com resolução de $60 x 60$ pixels, sensibilidade $<0,15{ }^{\circ} \mathrm{C}$ e faixa de temperatura de $-20^{\circ} \mathrm{C}$ a $250{ }^{\circ} \mathrm{C}$, seguindo-se a seguinte rotina:

(a) aferição da temperatura e da umidade do ar com termo-higrômetro digital no local do ensaio;

(b) posicionamento do termografista para aquisição de dados de emissividade e temperatura aparente refletida;

(c) determinação do valor da emissividade, conforme o método da fita padrão descrito na E1933-99a (AMERICAN..., 1999);

(d) determinação da temperatura aparente refletida, conforme método do refletor descrito na E1862-97 (AMERICAN..., 2010);

(e) captura de termograma da superfície frontal da parede (face revestida com cerâmica) após inserção dos dados de temperatura ambiente, umidade e temperatura aparente refletida; $\mathrm{e}$

(f) captura dos termogramas de toda a superfície frontal da parede e de cada placa cerâmica, da primeira até a sexta placa.

Após serem realizadas as inspeções, no software Flirtools foram processados os termogramas, determinadas as temperaturas médias da parte frontal (Ti), bem como da cerâmica $(\mathrm{Tci}, \mathrm{j})$, da região com defeito (Tdi,j) e da região sem defeito (Tndi,j), conforme ilustrado na Figura 5. Considerou-se $i$ o horário em que o termograma foi realizado, e $j$ a identificação da placa.

Com as temperaturas obtidas no processamento dos termogramas, foram determinados os parâmetros seguintes (Equações 1 e 2):

$\Delta T=T d_{i, j}-T n d_{i, j}$

Eq. 1

$V p=T_{i}-T_{i-1}$

Eq. 2

O Delta $\mathrm{T}(\Delta \mathrm{T})$ foi o parâmetro utilizado para a identificação e avaliação dos defeitos. A variação da temperatura média da face revestida da parede $(\mathrm{Vp})$ foi utilizada como referência do ganho de calor da superfície revestida com placa cerâmica, considerando que a fonte de calor responsável pelo aparecimento das regiões com defeito nos termogramas é, principalmente, a incidência direta do sol sobre a superfície revestida com a placa cerâmica.

\section{Figura 3 - Imagem digital do defeito e parede de alvenaria}

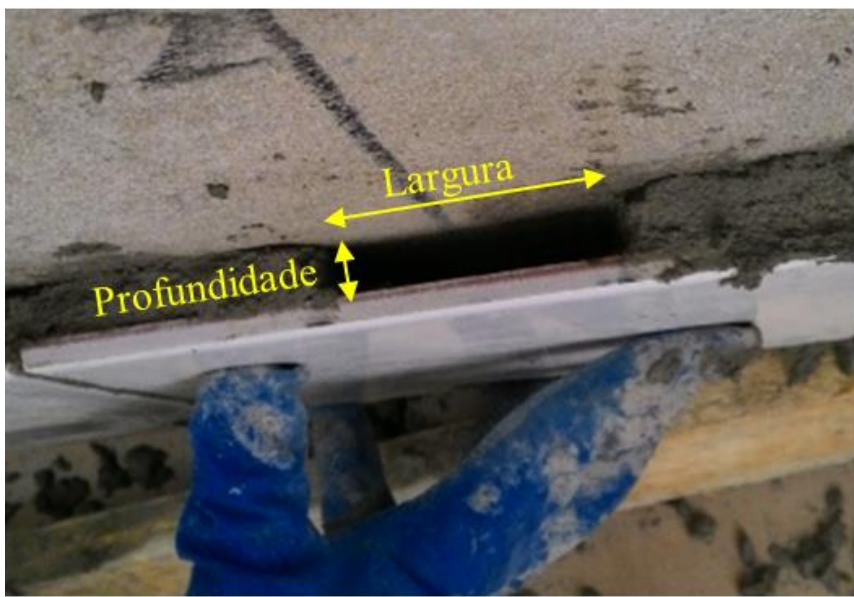

(a) Construção do defeito

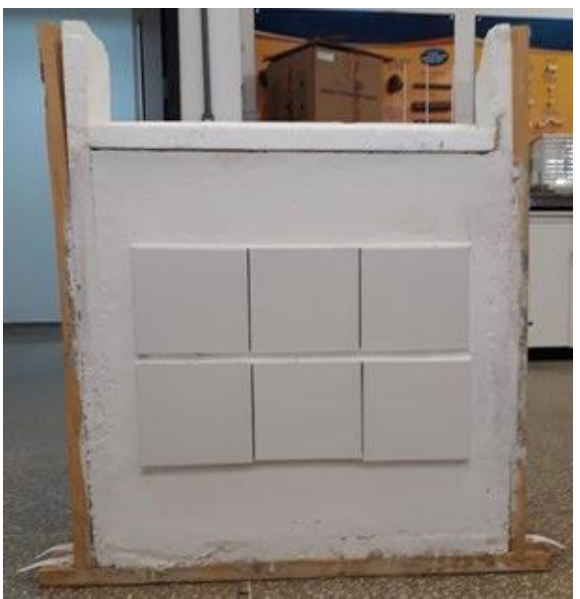

(b) Parede de alvenaria concluída 
Figura 4 - Representação gráfica das medições realizadas com a câmera infravermelha na orientação leste

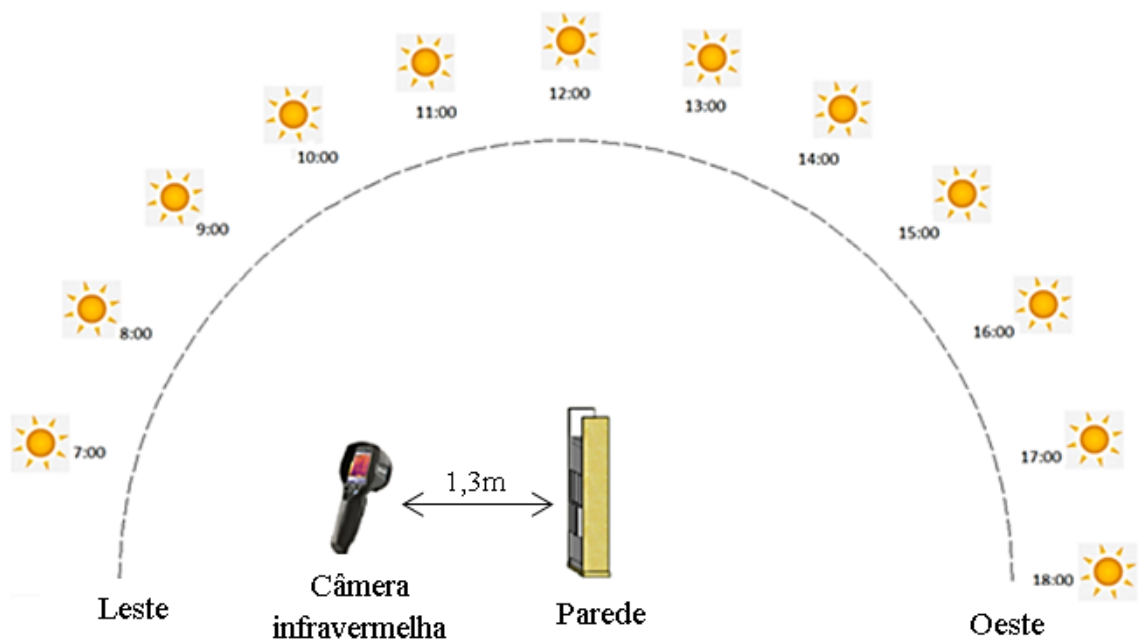

Figura 5 - Temperaturas mensuradas nos termogramas da parede de alvenaria: (a) face revestida; (b) placa cerâmica
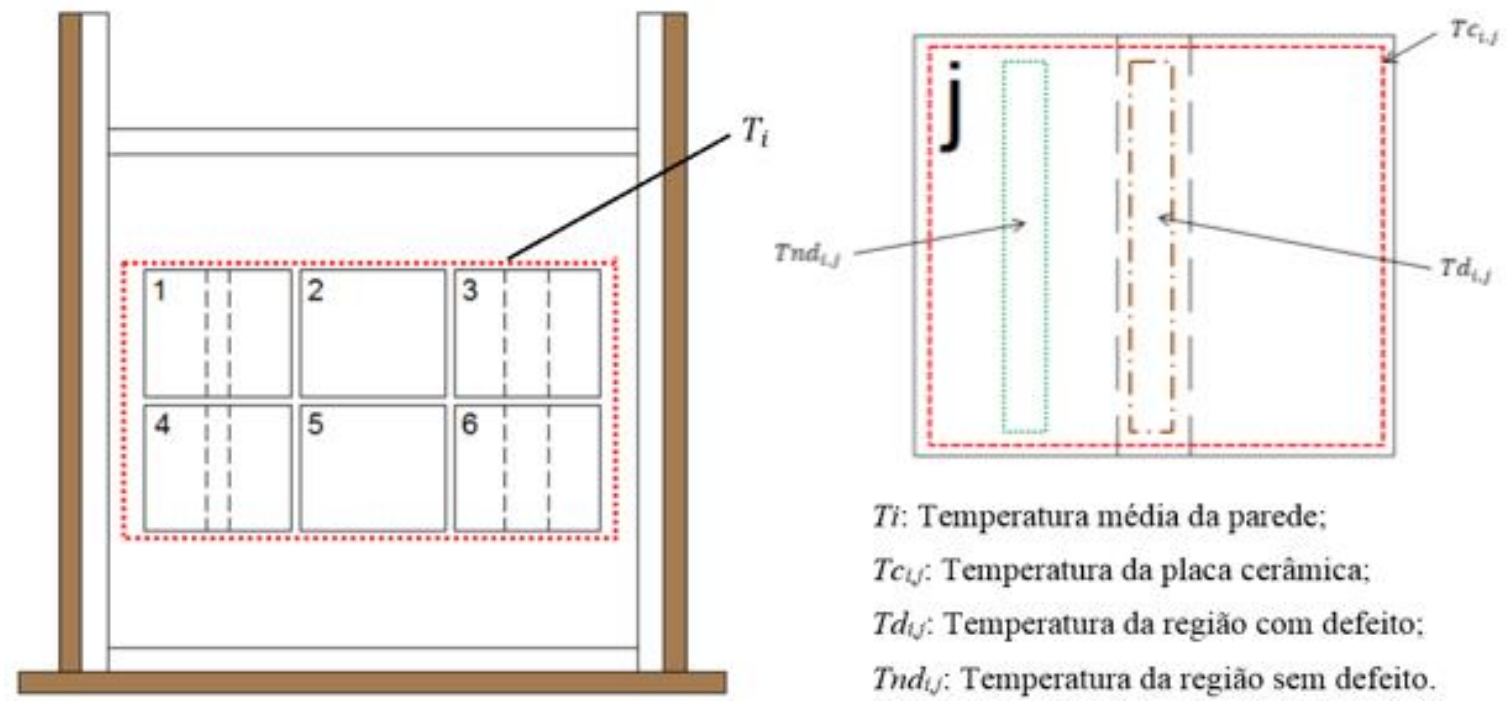

Ti: Temperatura média da parede;

$T c_{\ell}$ : Temperatura da placa cerâmica;

$T d_{i j:}$ : Temperatura da região com defeito:

Tnd $d_{i j}$ : Temperatura da região sem defeito.

Para analisar o comportamento ao longo do dia dos parâmetros estudados foram elaboradas figuras com os valores médios das medições dos três anos consecutivos. Já para a análise da influência das dimensões das regiões com defeito foi realizada uma análise estatística (ANOVA) com os valores de Delta T obtidos por ano para cada orientação. Para a análise estatística da dimensão das regiões com defeito escolheu-se o horário, por orientação, em que foram obtidos os maiores valores de Delta $\mathrm{T}$, representando o momento de melhor visibilidade dos defeitos. Desse modo, analisou-se a influência das dimensões (largura e profundidade) do defeito no Delta $T$, principal parâmetro utilizado na identificação e avaliação termográfica de defeitos e anomalias.

\section{Resultados e discussões}

A Figura 6 apresenta os resultados do Delta T correspondentes à avaliação termográfica do protótipo nas quatro orientações solares. As curvas mostram o valor médio do Delta $\mathrm{T}$ calculado a partir dos valores obtidos nos anos 2016, 2017 e 2018 das placas com defeito (1, 3, 4 e 6). Junto ao número da placa aparecem a largura e a profundidade do defeito. 


\section{Figura 6 - Comportamento do Delta T nas placas cerâmicas com defeito de assentamento nas quatro orientações solares}
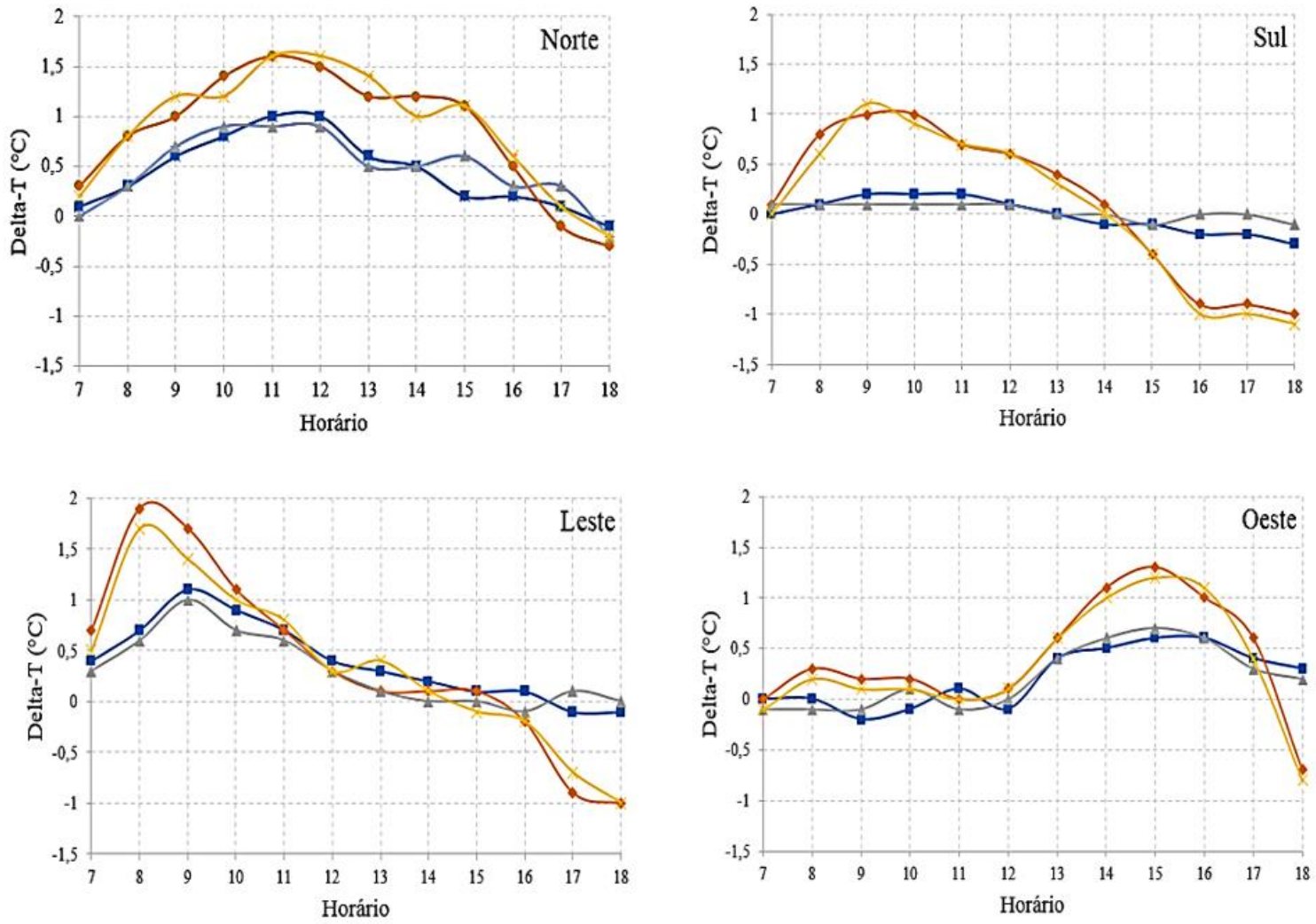

$\rightarrow$ (1) D 2,5 x 0,5 (3) D 5,0 x 0,5 (4) D 2,5 x 1,0 (6) D 5,0 x 1,0

Pode-se observar na Figura 6 que os máximos valores de Delta T (em módulo) foram obtidos durante os períodos de incidência direta do sol sobre o revestimento cerâmico, exceto no caso da fachada Sul, na qual o aparecimento do defeito no termograma se justifica pelo ganho de calor da parede com o aumento da temperatura ambiente. Por tais motivos, nesta orientação os valores máximos (em módulo) de Delta $\mathrm{T}$ foram inferiores aos das demais orientações.

A orientação Norte, que recebeu a incidência direta do sol, apresentou durante todo o dia valores positivos do Delta T. Já nas orientações Leste e Oeste os valores positivos de Delta T foram obtidos durante a manhã e à tarde, coincidindo com os momentos de incidência direta da radiação solar sob o revestimento cerâmico. Vários autores (EDIS; FLORES-COLEN; BRITO, 2015a; FREITAS; FREITAS; BARREIRA, 2014; LOURENÇO; MATIAS; FARIA, 2017; PAVÓN, 2017) relatam que, quando se tem incidência direta da fonte de calor sobre a superfície analisada, os defeitos com presença de vazio aparecem como áreas mais quentes no termograma, gerando valores positivos do Delta $\mathrm{T}$, como ocorreu no presente estudo.

Valores de Delta $\mathrm{T}$ acima de $0,3{ }^{\circ} \mathrm{C}$ podem ser utilizados como confirmação da presença de defeitos, garantindo, de fato, sua visibilidade no termograma. Desse modo, pode-se observar que nas orientações que receberam incidência direta do sol na face revestida com cerâmica em algum momento do dia (Norte, Leste e Oeste), foi possível detectar os defeitos de assentamento através da termografia, nas quatro placas cerâmicas, nos períodos de incidência direta do sol. No caso da fachada Sul, não foi possível confirmar, de acordo com esse critério, a presença do defeito de menor largura $(2,5 \mathrm{~cm})$, ou seja, o defeito de assentamento nas cerâmicas 1 e 4 . Na Figura 7 podem ser observados os termogramas correspondentes aos horários de máximo Delta T nas quatro orientações, verificando-se de fato que somente na orientação Sul os defeitos de assentamento de menor largura não foram identificados nos termogramas.

A não incidência direta do sol na face revestida não aumentou consideravelmente a temperatura da superfície frontal e, consequentemente, o fluxo de calor no sentido da face sem revestimento - face revestida não é suficiente para gerar diferenças da superfície nas placas de menores dimensões. Outros autores (BAUER et al., 2016a; CERDEIRA et al., 2011; CHENG; CHENG; CHIANG, 2008; CHOI et al., 2008) 
têm verificado que os defeitos de menores tamanhos aparecem no termograma com valores menores de Delta $\mathrm{T}$ e, a depender do fluxo de calor que atravessa a parede, pode ser que não sejam detectados no termograma.

De modo geral, observou-se que nos períodos de maior incidência do sol nas quatro orientações as placas 3 e 6 apresentaram os maiores valores de Delta T, o que indica que defeitos de maior largura, isto é, de maior área, poderão ser mais facilmente detectados pela termografia. Esse fato indica também que a largura do defeito foi a variável que, a priori, teve maior influência nos resultados de Delta T. Quando comparadas as placas de igual largura e diferentes profundidades entre si - as placas 1 e 4 ou as placas 3 e 6 -, não foi possível observar grandes diferenças nos valores ao longo do dia, o que pressupõe que a profundidade do defeito não influenciou os valores de Delta $\mathrm{T}$. Na prática, poderia indicar que diferenças na profundidade dos descolamentos nem sempre poderão ser detectadas.

Figura 7 - Termogramas onde foram obtidos os máximos valores de Delta T nas quatro orientações solares: Norte - $11 \mathrm{~h}$; Sul - 9h; Leste - $8 \mathrm{~h}$; e Oeste - 15h
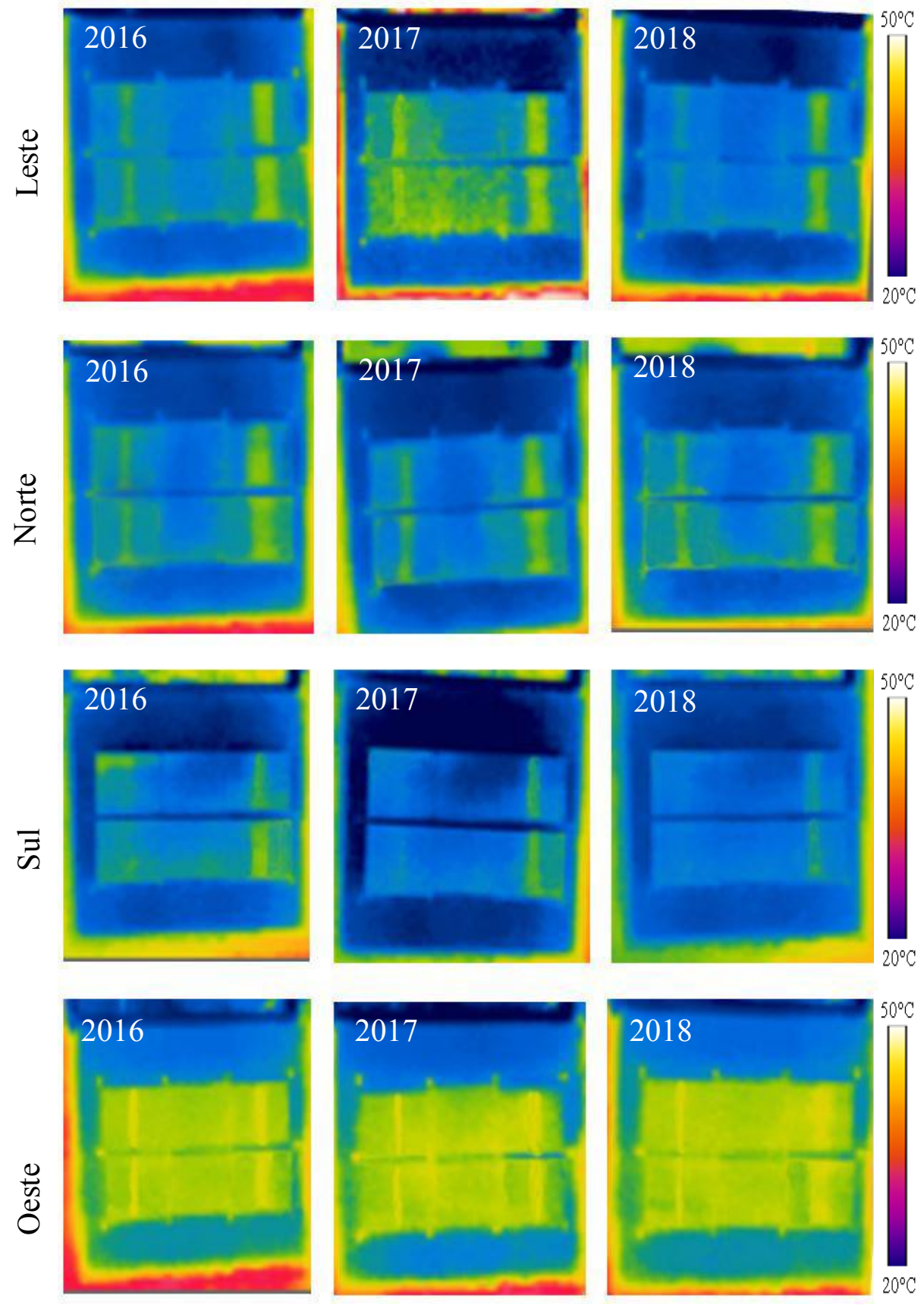

140 Tanaka, D.; Pavon, E. 
Como referência do ganho de calor na superfície revestida com placa cerâmica, foi utilizado o parâmetro Vp. Na Figura 8 pode-se observar a média de Vp calculada com os valores obtidos nos anos 2016, 2017 e 2018 , e os máximos valores desse parâmetro para cada orientação.

Analisando-se os parâmetros Delta T e Vp, verifica-se que os máximos valores de Delta T (Figura 6) foram obtidos nos momentos de máximo crescimento da temperatura da superfície revestida (Vp) (Figura 8) nas quatro orientações solares.

Com o aumento da temperatura ambiente e a incidência direta do sol sobre a face revestida, cresce a temperatura da superfície em relação ao interior da parede, aumentando também o fluxo de calor que atravessa a parede da superfície externa (face revestida) para a interna (traseira). Quando a face revestida recebe a incidência direta do sol, ganha calor mais rápido, incrementando rapidamente o fluxo de calor e, por conseguinte, aumentando a diferença de temperatura da área com defeito em relação à área sem defeito, ou seja, aumentando o Delta T. Esse fato justifica o comportamento obtido em relação aos valores máximos de Delta $\mathrm{T}$ e pode ser considerado um bom indicativo da escolha do momento de fazer a inspeção, considerando que existem programas computacionais que permitem simular previamente (antes da inspeção) a temperatura em diferentes pontos de paredes externas da edificação, como realizado em diversos estudos (EDIS et al., 2012; FOX et al., 2015; IBARRA-CASTANEDO et al., 2017; PAVÓN, 2017). Caso não seja possível realizar a simulação prévia, sugere-se que nas fachadas que recebem radiação solar direta em algum momento do dia a inspeção seja realizada durante o período de incidência direta do sol sobre o revestimento, sendo realizados no mínimo três termogramas com intervalos de $1 \mathrm{~h}$ entre eles.

Com base na hipótese de que a inspeção termográfica deve ser realizada no momento de melhor visualização do defeito, ou seja, no momento em que são obtidos os máximos valores de Delta $T$, foi realizada uma análise de variância (ANOVA) do tipo fatorial utilizando os valores de 2016, 2017 e 2018, correspondentes ao horário em que se obteve em média o máximo valor de Delta T para cada orientação (Norte - 11h; Sul 9h; Leste - 8h; e Oeste - 15h). Na Figura 9 estão apresentados os resultados da análise da influência das dimensões (largura e profundidade) dos defeitos de assentamento para cada orientação, mostrando os valores médios com intervalo de confiança de 0,95 . Destaca-se que foram realizadas quatro análises de variância, uma para cada orientação solar.

\section{Figura 8 - Comportamento da variação da temperatura média da face revestida da parede (Vp) nas quatro orientações solares}

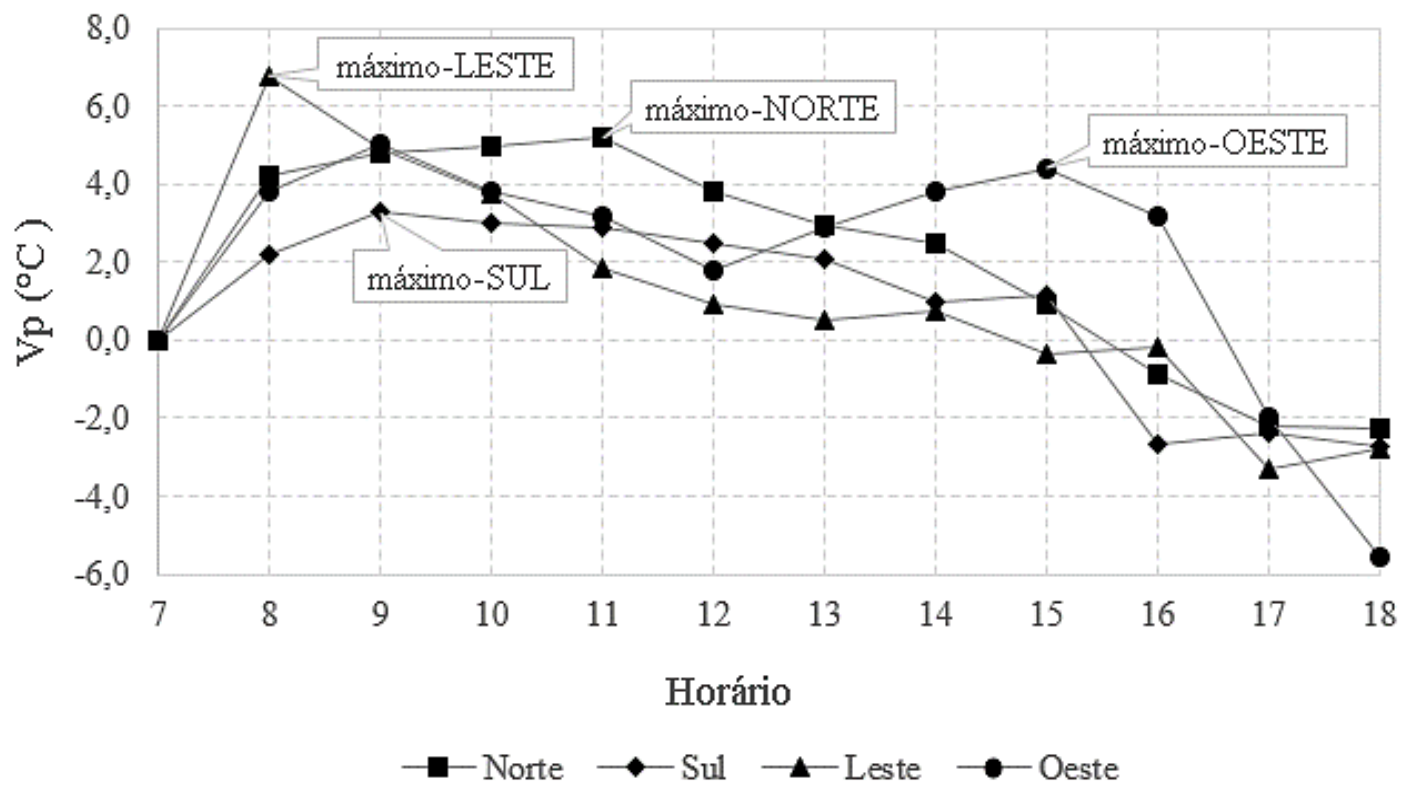


Figura 9 - Valores médios de Delta T para cada orientação solar, com intervalo de confiança de 0,95
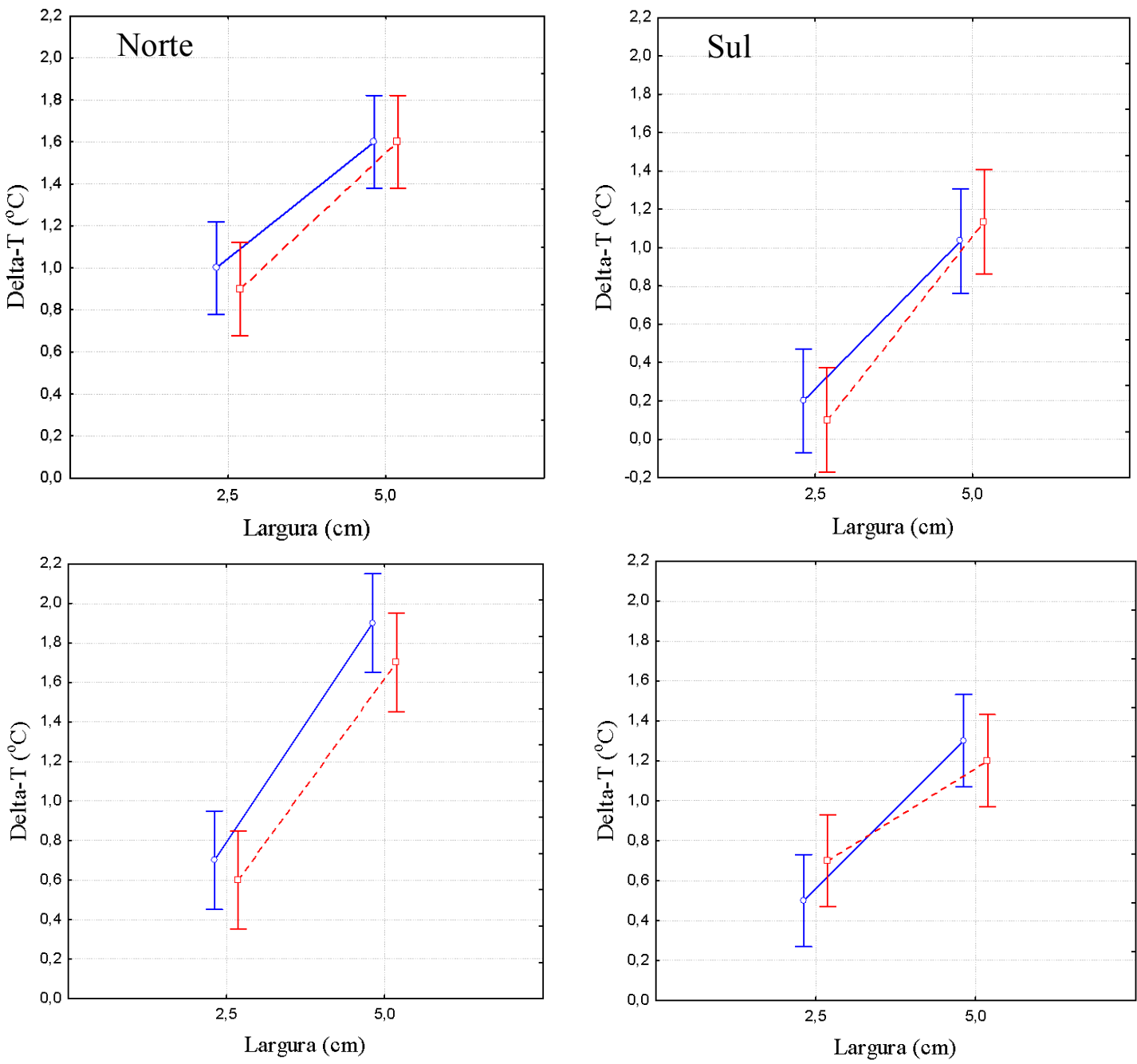

Observou-se na orientação Norte que as diferenças entre as médias geradas pela largura do defeito foram de $0,6^{\circ} \mathrm{C}$ e de $0,7^{\circ} \mathrm{C}$ para os defeitos de 0,5 e de $1,0 \mathrm{~cm}$ de profundidade respectivamente. $\mathrm{Na}$ orientação Sul as diferenças entre as médias geradas pela largura do defeito foram de $0,8{ }^{\circ} \mathrm{C}$ e de $0,1{ }^{\circ} \mathrm{C}$ para os defeitos de 0,5 $\mathrm{cm}$ e de $1,0 \mathrm{~cm}$ de profundidade respectivamente. Já para defeitos de igual largura, tanto na orientação Norte quanto na orientação Sul, as diferenças devido à profundidade não ultrapassaram $0,1{ }^{\circ} \mathrm{C}$ em nenhum dos casos.

Verificou-se na orientação Leste que as diferenças entre as médias geradas pela largura do defeito foram de $1,0^{\circ} \mathrm{C}$ e de $1,2{ }^{\circ} \mathrm{C}$ para os defeitos de $0,5 \mathrm{~cm}$ e de $1,0 \mathrm{~cm}$ de profundidade respectivamente. Na orientação Oeste as diferenças entre as médias geradas pela largura do defeito foram de $1,2{ }^{\circ} \mathrm{C}$ e de $0,5{ }^{\circ} \mathrm{C}$ para os defeitos de $0,5 \mathrm{~cm}$ e de $1,0 \mathrm{~cm}$ de profundidade respectivamente. Já para defeitos de igual largura, tanto na orientação Norte quanto na orientação Sul, as diferenças devido à profundidade não ultrapassaram $0,2{ }^{\circ} \mathrm{C} \mathrm{em}$ nenhum dos casos.

Desse modo, na Tabela 1, que apresenta os resultados da análise estatística, comprova-se que nas quatro orientações solares somente a largura teve influência significativa nos valores de Delta T. Já a profundidade e a combinação de largura versus profundidade não tiveram influência significativa nos valores do Delta $T$ no horário analisado, ou seja, no horário de máximo Delta T em cada orientação. 
Tabela 1 - Análise de variância do Delta T para cada orientação solar, com intervalo de confiança de 0,95

\begin{tabular}{|c|c|c|c|c|c|c|c|}
\hline & Efeito & $\begin{array}{c}\text { Soma } \\
\text { quadrada } \\
\text { (SQ) } \\
\end{array}$ & $\begin{array}{c}\text { Graus de } \\
\text { liberdade } \\
\text { (GL) } \\
\end{array}$ & $\begin{array}{c}\text { Média dos } \\
\text { quadrados } \\
\text { (MQ) }\end{array}$ & $\begin{array}{c}\text { F } \\
\text { calculado }\end{array}$ & $\mathbf{p}$ & Resultado \\
\hline \multirow{5}{*}{ Norte } & Intercepto & 19,50750 & 1 & 19,50750 & 709,3636 & 0,000000 & \\
\hline & Largura & 1,26750 & 1 & 1,26750 & 46,0909 & 0,000139 & Significativo \\
\hline & Profundidade & 0,00750 & 1 & 0,00750 & 0,2727 & 0,615656 & $\begin{array}{l}\text { Não } \\
\text { significativo }\end{array}$ \\
\hline & $\begin{array}{l}\text { Largura } \\
\text { *Profundidade }\end{array}$ & 0,00750 & 1 & 0,00750 & 0,2727 & 0,615656 & $\begin{array}{l}\text { Não } \\
\text { significativo }\end{array}$ \\
\hline & Erro & 0,22000 & 8 & 0,02750 & & & \\
\hline \multirow{5}{*}{ Sul } & Intercepto & 4,563333 & 1 & 4,563333 & 109,5200 & 0,000006 & \\
\hline & Largura & 2,613333 & 1 & 2,613333 & 62,7200 & 0,000047 & Significativo \\
\hline & Profundidade & 0,000000 & 1 & 0,000000 & 0,0000 & 1,000000 & $\begin{array}{l}\text { Não } \\
\text { significativo }\end{array}$ \\
\hline & $\begin{array}{l}\text { Largura } \\
\text { *Profundidade }\end{array}$ & 0,030000 & 1 & 0,030000 & 0,7200 & 0,420806 & $\begin{array}{l}\text { Não } \\
\text { significativo }\end{array}$ \\
\hline & Erro & 0,333333 & 8 & 0,041667 & & & \\
\hline \multirow{5}{*}{ Leste } & Intercepto & 18,00750 & 1 & 18,00750 & 514,5000 & 0,000000 & \\
\hline & Largura & 3,96750 & 1 & 3,96750 & 113,3571 & 0,000005 & Significativo \\
\hline & Profundidade & 0,06750 & 1 & 0,06750 & 1,9286 & 0,202354 & $\begin{array}{l}\text { Não } \\
\text { significativo }\end{array}$ \\
\hline & $\begin{array}{l}\text { Largura } \\
\text { *Profundidade }\end{array}$ & 0,00750 & 1 & 0,00750 & 0,2143 & 0,655760 & $\begin{array}{l}\text { Não } \\
\text { significativo }\end{array}$ \\
\hline & Erro & 0,28000 & 8 & 0,03500 & & & \\
\hline \multirow{5}{*}{ Oeste } & Intercepto & 10,26750 & 1 & 10,26750 & 342,2500 & 0,000000 & \\
\hline & Largura & 1,26750 & 1 & 1,26750 & 42,2500 & 0,000188 & Significativo \\
\hline & Profundidade & 0,00750 & 1 & 0,00750 & 0,2500 & 0,630536 & $\begin{array}{l}\text { Não } \\
\text { significativo }\end{array}$ \\
\hline & $\begin{array}{l}\text { Largura } \\
\text { *Profundidade }\end{array}$ & 0,06750 & 1 & 0,06750 & 2,2500 & 0,172003 & $\begin{array}{l}\text { Não } \\
\text { significativo }\end{array}$ \\
\hline & Erro & 0,24000 & 8 & 0,03000 & & & \\
\hline
\end{tabular}

A análise da influência das dimensões (largura e profundidade) dos defeitos de assentamento no horário de máximo Delta $\mathrm{T}$ para cada orientação revelou que a largura teve influência significativa nos valores de Delta $\mathrm{T}$ nas quatro orientações. Diferenças na largura dos defeitos terão maior probabilidade de ser detectado, o que, do ponto de vista prático, facilita a avaliação do desempenho de sistemas de revestimento cerâmico externos, considerando que os critérios de desempenho exigidos pela NBR 15575-4 (ABNT, 2013) para sistemas de vedação verticais internos e externos estão relacionados com a mensuração da área da manifestação patológica. $\mathrm{O}$ fato de maior largura gerar maiores valores de Delta $\mathrm{T}$, após o processamento dos termogramas, independentemente da orientação solar da fachada, poderá ser um bom indicativo para a identificação e análise da gravidade dos descolamentos, quando associado a seu tamanho.

Em relação à profundidade, verificou-se que não teve influência significativa nos valores de Delta $\mathrm{T}$ nas quatro orientações. Nesse caso, o aumento da profundidade da camada de ar, que caracterizou o defeito de assentamento, não gerou diferenças de temperatura na superfície do revestimento. Do ponto de vista da aplicação prática, esse fato pode gerar dificuldades no processo de inspeção e diagnóstico dos defeitos de assentamento que podem gerar descolamentos utilizando a termografia, ao não ser possível associar em defeitos de assentamento com áreas aproximadamente iguais maiores valores de Delta $\mathrm{T}$ à profundidade do defeito.

É importante ressaltar que a profundidade do descolamento nas fachadas cerâmicas pode estar associada somente à placa cerâmica ou à placa cerâmica junto a uma camada (ou várias) de argamassa que se separam do substrato. Essa condição, em boa parte dos casos, pode ser detectada com uma rigorosa inspeção visual, sendo mais importante para o termografista poder associar os valores do Delta $\mathrm{T}$ à área descolada, como exigido pela norma de desempenho. Desse modo, o fato de se ter quantificado e analisado estatisticamente a influência da largura na detecção dos defeitos de assentamento que podem gerar descolamentos, utilizando o 
parâmetro Delta $\mathrm{T}$, torna-se um resultado promissor no campo das inspeções de revestimentos cerâmicos com termografia de infravermelho.

\section{Considerações finais}

Com base nas características dos experimentos, no comportamento das variáveis estudadas e na análise estatística realizada no presente estudo, conclui-se que a avaliação termográfica de descolamentos cerâmicos com termografia de infravermelho pode ser realizada durante períodos com e sem incidência do sol sobre o revestimento analisado, dependendo a identificação dos defeitos de seu tamanho.

Foi possível visualizar nos termogramas defeitos que simularam a presença de descolamentos com largura de $2,5 \mathrm{~cm}$ até $5 \mathrm{~cm}$ e profundidade de $0,5 \mathrm{~cm}$ até $1 \mathrm{~cm}$ nos períodos de incidência direta do sol sob o revestimento cerâmico. $\mathrm{Na}$ orientação Sul, sem a incidência direta, não foi possível detectar defeitos de 2,5 $\mathrm{cm}$ de largura.

Os máximos valores de Delta $\mathrm{T}$, que indicaram a presença de defeitos de assentamento da placa cerâmica, foram obtidos nos momentos de máximo crescimento da temperatura da superfície revestida nas quatro orientações solares, o que ressalta a necessidade da simulação prévia da temperatura no revestimento.

A análise da influência das dimensões (largura e profundidade) dos defeitos de assentamento no horário de máximo Delta $T$ para cada orientação solar revelou que a largura teve influência significativa nos valores de Delta $\mathrm{T}$ nas quatro orientações, independentemente da profundidade do defeito. Já a profundidade não teve influência significativa em nenhuma orientação solar.

Diferenças na largura, isto é, na área dos defeitos, terão maior probabilidade de ser detectadas, o que facilita a avaliação do desempenho de sistemas de revestimento cerâmico externos com a termografia de infravermelho, considerando que os critérios de desempenho exigidos pela norma NBR 15575-4 (ABNT, 2013) para sistemas de vedação verticais estão relacionados com a mensuração da área da manifestação patológica.

Como o presente estudo se limitou a estudar descolamentos simulados a partir de falhas de assentamento retangulares no revestimento cerâmico em condições secas, sugere-se para próximos trabalhos que sejam avaliados defeitos de diferente geometria e analisada a influência da presença de umidade no revestimento cerâmico.

\section{Referências}

AMERICAN SOCIETY FOR TESTING AND MATERIALS. E1862-97: standard test methods for measuring and compensating for reflected temperature using infrared imaging radiometers. Philadelphia, 2010.

AMERICAN SOCIETY FOR TESTING AND MATERIALS. E1933-99a: standard test methods for measuring and compensating for emissivity using infrared imaging radiometers. Philadelphia, 1999.

ASSOCIAÇÃO BRASILEIRA DE NORMAS TÉCNICAS. NBR 15575-4: edificações habitacionais: desempenho: parte 4: sistemas de vedações verticais internas e externas - SVVIE. Rio de Janeiro, 2013.

BAGAVATHIAPPAN, S. et al. Infrared thermography for condition monitoring: a review. Infrared Physics \& Technology, v. 60, p. 35-55, 2013.

BARREIRA, E.; FREITAS, V. P. Evaluation of building materials using infrared thermography. Construction and Building Materials, v. 21, n. 1, p. 218-224, 2007.

BAUER, E. et al. Criteria for identification of ceramic detachments in building facades with infrared thermography. Recent Developments in Building Diagnostic, v. 5, p. 51-68, 2016 a.

BAUER, E. et al. Facades inspection with infrared thermography: cracks evaluation. Journal of Building Pathology and Rehabilitation, v. 1, n. 2, p. 1-7, 2016b.

BAUER, E.; MILHOMEM, P. M.; AIDAR, L. A. G. Evaluating the damage degree of cracking in facades using infrared thermography. Journal of Civil Structural Health Monitoring, v. 8, n. 3, p. 517-528, 2018.

CALDEIRA, M. M. et al. Potentialities of infrared thermography to assess damage in bonding between concrete and GFRP. Revista IBRACON de Estruturas e Materiais, v. 8, n. 3, p. 296-322, 2015.

144 Tanaka, D.; Pavon, E. 
CERDEIRA, F. et al. Applicability of infrared thermography to the study of the behaviour of stone panels as building envelopes. Energy and Buildings, v. 43, n. 8, p. 1845-1851, 2011.

CHENG, C.-C.; CHENG, T.-M.; CHIANG, C.-H. Defect detection of concrete structures using both infrared thermography and elastic waves. Automation in Construction, v. 18, p. 87-92, 2008.

CHEW, M. Y. L. Assessing building facades using infra-red thermography. Structural Survey, v. 16, p. 81$86,1998$.

CHOI, M. et al. Quantitative determination of a subsurface defect of reference specimen by lock-in infrared thermography. NDT \& E International, v. 41, n. 2, p. 119-124, 2008.

COELHO, T. C. C. et al. Desempenho térmico e absortância solar de telhas de fibrocimento sem amianto submetidas a diferentes processos de envelhecimento natural. Ambiente Construído, Porto Alegre, v. 17, n. 1, p. 147-161, jan./mar. 2017.

COTIČ, P. et al. Determination of the applicability and limits of void and delamination detection in concrete structures using infrared thermography. NDT \& E International, v. 74, p. 87-93, 2015.

DUFOUR, M. B.; DEROME, D.; ZMEUREANU, R. Analysis of thermograms for the estimation of dimensions of cracks in building envelope. Infrared Physics \& Technology, v. 52, n. 2-3, p. 70-78, 2009.

EDIS, E.; FLORES-COLEN, I.; BRITO, J. Building thermography: detection of delamination of adhered ceramic claddings using the passive approach. Journal of Nondestructive Evaluation, v. 34, n. 268, p. 113, 2015a.

EDIS, E.; FLORES-COLEN, I.; BRITO, J. Passive thermographic detection of moisture problems in façades with adhered ceramic cladding. Construction and Building Materials, v. 51, p. 187-197, 2014.

EDIS, E.; FLORES-COLEN, I.; BRITO, J. Passive thermographic inspection of adhered ceramic claddings: limitations and conditioning factors. Journal of Performance of Constructed Facilities, p. 737-747, dec. 2012.

EDIS, E.; FLORES-COLEN, I.; BRITO, J. Quasi-quantitative infrared thermographic detection of moisture variation in facades with adhered ceramic cladding using principal component analysis. Building and Environment, v. 94, p. 97-108, 2015 b.

FERRARINI, G. et al. Thermal response measurement of building insulating materials by infrared thermography. Energy and Buildings, v. 133, p. 559-564, 2016.

FOX, M. et al. Time-lapse thermography for building defect detection. Energy and Buildings, v. 92, p. 95 106, 2015.

FREITAS, S. S.; FREITAS, V. P.; BARREIRA, E. Detection of façade plaster detachments using infrared thermography: a nondestructive technique. Construction and Building Materials, v. 70, p. 80-87, 2014.

GARRIDO, I. et al. Thermographic methodologies used in infrastructure inspection: a review: postprocessing procedures. Applied Energy, v. 266, p. 114857, 2020.

IBARRA-CASTANEDO, C. et al. Solar loading thermography: time-lapsed thermographic survey and advanced thermographic signal processing for the inspection of civil engineering and cultural heritage structures. Infrared Physics and Technology, v. 82, p. 56-74, 2017.

KOMINSKY, J. R. et al. Passive infrared thermography: a qualitative method for detecting moisture anomalies in building envelopes. Tedford \& Pond, p. 1-11, 2007.

LOURENÇO, T.; MATIAS, L.; FARIA, P. Anomalies detection in adhesive wall tiling systems by infrared thermography. Construction and Building Materials, v. 148, p. 419-428, sep. 2017.

MARIO, M. Uso da termografia como ferramenta não destrutiva para avaliação de manifestações patológicas ocultas. Porto Alegre, 2011. Trabalho de Conclusão de Curso (Engenharia Civil) Universidade Federal do Rio Grande do Sul, Porto Alegre, 2011.

PAVÓN, E. Critérios e padrões de comportamento para avaliação de descolamentos cerâmicos com termografia de infravermelho. Brasília, 2017. Tese (Doutorado em Estruturas e Construção Civil) Departamento de Engenharia Civil e Ambiental, Universidade de Brasília, Brasília, 2017.

ROCHA, J. H. A. et al. Detecção de infiltração em áreas internas de edificações com termografia infravermelha: estudo de caso. Ambiente Construído, Porto Alegre, v. 18, n. 4, p. 329-340, out./dez. 2018. 
SANTOS, C. F. et al. Utilização da termografia infravermelha para detecção de focos de umidade em paredes internas de edificações. Ambiente Construído, Porto Alegre, v. 19, n. 1, p. 105-127, jan./mar. 2019.

SHAM, F. C.; CHEN, N.; LONG, L. Surface crack detection by flash thermography on concrete surface. Insight: Non-Destructive Testing and Condition Monitoring, v. 50, n. 5, p. 240-243, 2008.

SILVA, D. D. S. Diagnóstico de patologias em fachadas utilizando termografia. Porto, 2012. Dissertação (Mestrado em Engenharia Civil) - Engenharia Civil, Universidade do Porto, Porto, 2012.

SIMÕES, I. et al. IR thermography used to detect thin defects versus numerical simulation results. In: INTERNATIONAL CONFERENCE ON QUANTITATIVE INFRARED THERMOGRAPHY, 11. Napoles, 2012. Proceedings [...] Napoles, 2012.

YOUCEF, M. H. A. L. et al. Quantitative infrared thermography in situ quantitative diagnosis of insulated building walls using passive infrared thermography. In: INTERNATIONAL CONFERENCE ON QUANTITATIVE INFRARED THERMOGRAPHY, 11., Napoles, 2012. Proceedings [...] Napoles, 2012.

\section{Diandra Tanaka}

Coordenação de Infraestrutura Universidade Federal do Oeste da Bahia | Rua José Seabra de Lemos, 316, Recanto dos Pássaros | Barreiras - BA - Brasil | CEP 47808-041 | Tel.: (77) 3614-3521 | E-mail: dtanaka_engcivil@hotmail.com

\section{Elier Pavon}

Centro das Ciências Exatas e das Tecnologias | Universidade Federal do Oeste da Bahia | Tel.: (77) 3614-3116 | E-mail: elierpavon@gmail.com

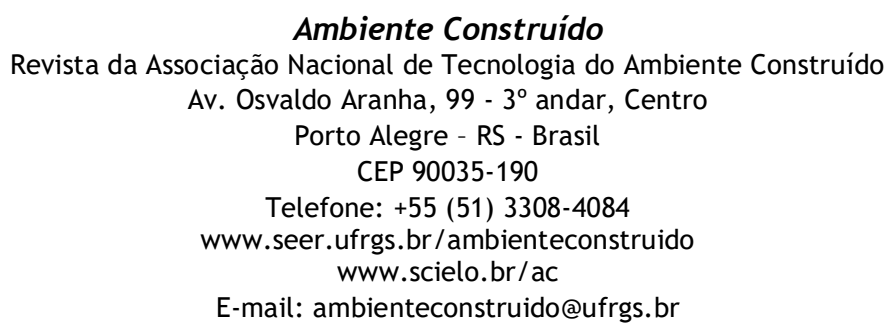

